\title{
Nutcracker syndrome complicated by left renal vein thrombosis and resolution with anticoagulation: A case report and review of the literature
}

\author{
Ramón Peces ${ }^{*}$, María Maldonado ${ }^{1}$, Emilio Cuesta $^{2}$, Carlos Peces ${ }^{3}$, Julián Nevado $^{4,5}$ and Rafael Selgas ${ }^{1}$ \\ ${ }^{1}$ Servicio de Nefrología, Hospital Universitario La Paz, IdiPAZ, Universidad Autónoma, Spain \\ ${ }^{2}$ Servicio de Radiología, Hospital Universitario La Paz, IdiPAZ, Universidad Autónoma, Spain \\ ${ }^{3}$ Area de Tecnologías de la Información, SESCAM, Spain \\ ${ }^{4}$ Instituto de Genética Médica y Molecular (INGEMM)-IdiPAZ, Hospital Universitario La Paz, Universidad Autónoma, Spain \\ ${ }^{5}$ CIBERER, Centro de Investigación Biomédica en Red de Enfermedades Raras, ISCIII, Spain
}

\begin{abstract}
The nutcracker syndrome is the compression of the left renal vein (LRV) between the superior mesenteric artery and the abdominal aorta. LRV thrombosis associated with nutcracker syndrome is extremely rare with only a few cases reported. However, the predisposing factors of LRV thrombosis complicating nutcracker syndrome remain unclear. We report the case of a young woman diagnosed of thalassemia minor and hypothyroidism who received oral contraceptives during 12 months. She presented with acute onset of left side flank pain and a computed tomography (CT) revealed LRV thrombosis caused by local compression by anterior nutcracker syndrome. The patient received bemiparin 5,000 U/day subcutaneously for one week, later converted to oral acenocoumarol. Six months afterwards doppler ultrasound (DU) revealed resolution of her LRV thrombosis. A CT at 9 months confirmed the complete resolution of the thrombus, persistent LRV compression by nutcracker syndrome, left gonadal vein dilatation and pelvic varices. On thrombophilia testing, at 15 months, she was also found to have heterozygous factor V Leiden mutation. After 23 months of anticoagulation, a new CT with three-dimensional reconstruction showed the complete LRV recanalization and a decrease of the left gonadal vein dilation. This case demonstrates that LRV thrombosis should be evaluated for risk factors including thrombophilia conditions. CT and DU were effective in documenting LRV thrombosis, their evolution and the underlying lesions non-invasively and long-term anticoagulation was an efficient and safe treatment. We also reviewed the reported cases of LRV thrombosis complicating nutcracker syndrome and discussed the clinical facts and the management.
\end{abstract}

\section{Introduction}

The nutcracker syndrome is an uncommon clinical entity caused by extrinsic compression of the LRV with two anatomical variants: anterior with the LRV compression between the superior mesenteric artery and the abdominal aorta or posterior between the aorta and the vertebral column $[1,2]$. This condition can cause an asymptomatic dilatation of the distal portion of the LRV or produce macro or micro hematuria, gonadal vein dilatation, gonadal varices, varicocele, ovarian vein syndrome, pelvic congestion syndrome, orthostatic proteinuria and back pain [1-3]. Confirmation diagnosis is by DU, magnetic resonance imaging (MRI) and/or CT [1-3]. Treatment can vary, depending on patient characteristics and the severity of the symptoms, while conservative treatment, open surgery, and endovascular or extravascular surgery may be employed [4].

Thrombosis of LRV may be idiopathic or influenced by coexisting hypercoagulable risk factors [5-8]. Some studies consider venous compression by anatomic variations in the pancreas mimicking nutcracker syndrome to be the cause of thrombosis of LRV and other veins, perhaps because of retrograde stasis $[9,10]$. However, the LRV thrombosis is a very rare complication in the isolated nutcracker syndrome with only 4 cases reported [11-14]. In addition, the predisposing factors of LRV thrombosis complicating nutcracker syndrome remain unclear. We report a new case in a 24 -year-old female with anterior nutcracker syndrome which debuted with LRV thrombosis and was treated with chronic anticoagulation resulting in complete recanalization of the LRV thrombosis. To our knowledge this is the first case of LRV thrombosis complicating nutcracker syndrome with several associated risk factors (genetic and acquired) for hypercoagulability such as thalassemia minor, Factor V Leiden heterozygosity and oral contraceptive treatment, successfully treated with long-term anticoagulation. We also performed a review of the literature.

\section{Case report}

A 24-year-old Caucasian woman presented with complaint of sudden onset of left side flank pain and vomiting for 5 days. There was no history of voiding difficulty or burning micturition. No past history of renal calculus disease or any surgical intervention was noted. At the age of 12 years she was diagnosed of thalassemia minor (microcytosis and hypochromia) and hypothyroidism and received treatment

*Correspondence to: Ramón Peces, Servicio de Nefrología, Hospital Universitario La Paz, Spain, Tel: 34917277151; Fax: Fax: 34917277382; E-mail: ramon.peces@salud.madrid.org

Key words: anticoagulation, factor $V$ leiden mutation, left renal vein thrombosis, nutcracker syndrome, oral contraceptives, thalassemia minor

Received: April 18, 2020; Accepted: May 04, 2020; Published: May 07, 2020 
with levothyroxine 112 micrograms/day. On physical examination, tenderness was noted over left flank, but did not reveal any masses or vascular murmurs and rest of the abdominal examination was normal. She had an arterial blood pressure of $100 / 60 \mathrm{mmHg}$, a regular heart rate of 72 beats/min and a respiratory rate of 16 breaths/min. Her chest was clear to auscultation on both sides and she had normal heart sounds. Both legs presented tight non foveal edema down to her knees. The Hoffman sign was negative and her calves were pain free. The peripheral arterial pulses were symmetrical. The weight was $50 \mathrm{Kg}$ and body mass index (BMI) was $19.3 \mathrm{Kg} / \mathrm{m}^{2}$. The results of the blood count revealed: hemoglobin $12 \mathrm{~g} / \mathrm{dl}$, mean corpuscular volume (MCV) $73.7 \mathrm{fl}$, mean corpuscular hemoglobin (MCH) $21.3 \mathrm{pg}$, mean corpuscular hemoglobin concentration (MCHC) $28.9 \mathrm{~g} / \mathrm{dl}$, hematocrit $41.5 \%$, and red blood cells (RBC) $5.63 \times 10^{6} / \mu$ l. Urinalysis was normal. Coagulation profile and platelet counts were also normal. Her renal function was normal with an estimated glomerular filtration rate (eGFR) of $124 \mathrm{ml} / \mathrm{min} / 1.73 \mathrm{~m}^{2}$ according to chronic kidney disease epidemiology collaboration (CKD-EPI) formula for Cystatin $\mathrm{C}$ and proteinuria was negative. A CT of the abdomen showed compression of the LRV caused by the superior mesenteric artery and the abdominal aorta, leading to dilation of the proximal segment, with an intraluminal thrombus and with thickening of the walls (Figure 1A and 1B) and dilation of the collateral peri-renal and peri-ureteral venous system. Right kidney and bladder were normal. Family history revealed that her father, mother and two brothers also had hypothyroidism. Her father and paternal grandmother also had thalassemia minor. Her maternal grandfather presented a stroke at the age of 40 years. At the age of 23 years the patient received oral contraceptive treatment (Drosure ${ }^{\circ}$ ) that was maintained during 12 months. At admission oral contraceptive was discontinued. She received intravenous fluids for hydration and immediate anticoagulant therapy was started, using bemiparin 5,000 U/day, subcutaneously, of for 7 days. Patient was switched over to oral acenocoumarol therapy afterwards, which was then continued for 15 months. In follow-up at 6 months, DU showed that the thrombus found in the previous test had disappeared, good phasic flows in the LRV with no clinical findings suggestive of post-thrombotic syndrome. A control CT at 9 months confirmed the complete resolution of the thrombus, left gonadal vein dilatation (diameter $9 \mathrm{~mm}$ ) and ipsilateral pelvic varices. The angle between aorta and superior mesenteric artery was approximately $17^{\circ}$ (Figure 1C). After 15 treatment months, oral anticoagulation was stopped for 2 weeks (was changed to bemiparin) to ascertain the thrombophilia profile, which showed Factor V Leiden heterozygote mutation (G1691A). Her mother and 2 brothers also showed to be carriers of Factor V Leiden heterozygote mutation. Anticoagulation with acenocoumarol was restarted and continued lifelong. Renal function remained normal (eGFR $123 \mathrm{ml} / \mathrm{min} / 1.73$ $\mathrm{m}^{2}$ ) and proteinuria negative throughout the follow-up period. After 23 anticoagulation months, a new CT of the abdomen with three dimensional reconstruction showed compression of the LRV caused by the superior mesenteric artery and the abdominal aorta, leading to dilation of the proximal segment, without evidence of thrombus, a decrease of the venous varicosities of the renal pelvis, ureter, and dilation of the left gonadal vein (diameter $7 \mathrm{~mm}$ ) (Figure $1 \mathrm{D}$ and $1 \mathrm{E})$.

\section{Discussion}

Anterior nutcracker syndrome is usually caused by the trapping of the LRV between the superior mesenteric artery and the abdominal aorta. Posterior nutcracker syndrome is caused by the compression of the retroaortic LRV between the abdominal aorta and the vertebral column $[1,2]$. The true prevalence of nutcracker syndrome is unknown, although it is known that it occurs predominantly in healthy, thin individuals between 20 and 40 years of age and preferentially in women [1-3]. However, it might be underdiagnosed. Clinically, macro and micro hematuria is the most common finding, followed by proteinuria, pain on the left flank side, dyspareunia, dysmenorrhea, dysuria, varicoceles, and pelvic varices.
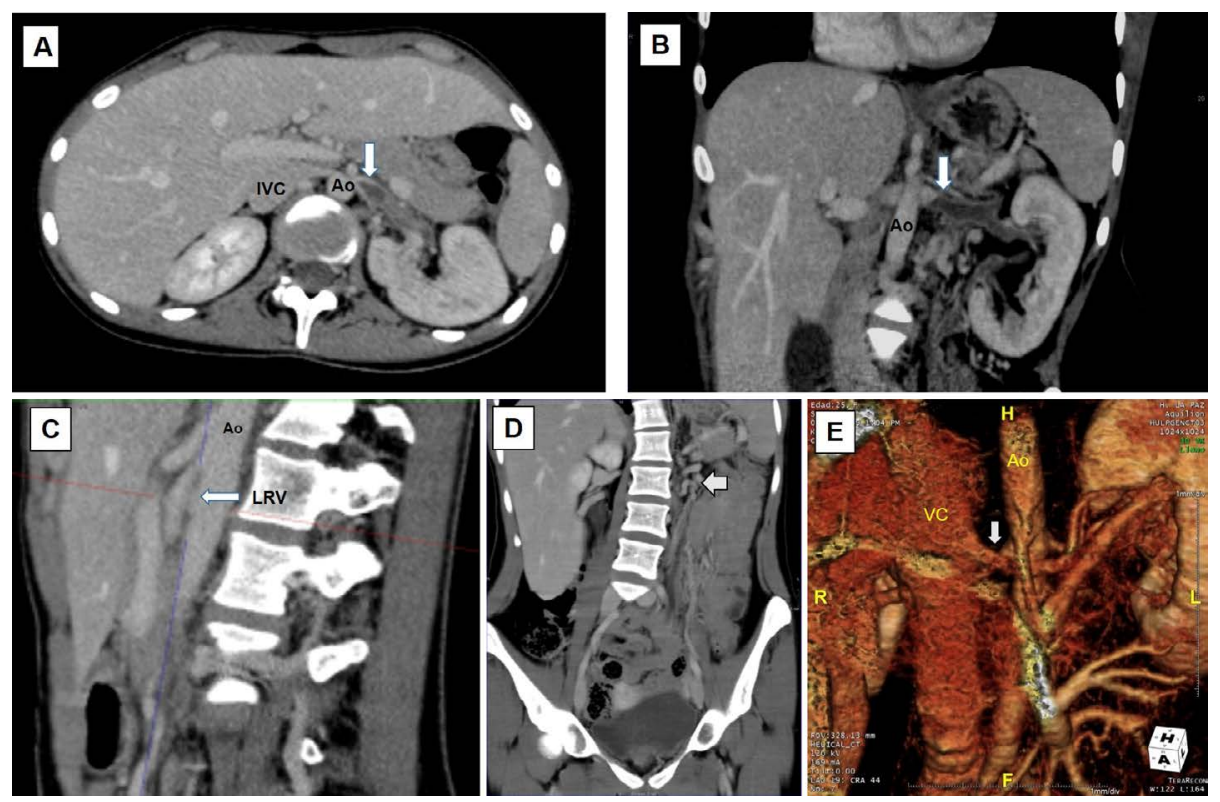

Figure 1. A and B) Axial and coronal CT imaging showing the left renal vein compressed between the superior mesenteric artery and the abdominal aorta (Ao) prior to entry in the inferior vena cava (VC) and a filling defect within the proximal portion of the left renal vein caused by the thrombus (arrow). There was also dilation of the left peri-renal and peri-ureteral venous system. C) Sagital CT imaging showing an angle of $17^{\circ}$ between the superior mesenteric artery and the abdominal aorta (Ao). D) Coronal CT imaging showing dilation of the collateral peri-renal venous system, dilation of the left gonadal vein (arrow) and ipsilateral pelvic varices. E) Coronal CT imaging with three-dimensional reconstruction showing the left renal vein (arrow) compressed between the superior mesenteric artery and the abdominal aorta (Ao) with complete disappearance of the thrombosis after 23 months of anticoagulation. There was no apparent impeded outflow from the left renal vein into the inferior vena cava (VC) 
Renal vein thrombosis is a rare condition. According to Virchow' triad, endothelial injury, hypercoagulability and stasis are the principal pathological factors responsible [6-8]. Generally, thrombotic events involve at least two factors, although one may be sufficient. It is more common in nephrotic syndrome, in severely hypotensive neonates, traumas, surgery, infections, neoplasias, vasculitis, venous compressions, contraceptives and myeloproliferative diseases [6]. There is also thrombophilia of genetic origin. Thalassemia syndromes are a heterogeneous group of hemoglobin disorders due to decreased or absent production of normal globin chains that can be broadly characterized as $\alpha$ - or $\beta$-thalassemias, depending on the defective globin chain [15]. The $\alpha$-thalassemias are the most common genetic diseases worldwide and are characterized by a reduction or complete absence of a-globin gene expression. Thalassemia minor is a disorder with a high prevalence in Spain characterized by a hypercoagulable state. There is evidence for increased risk of thrombosis in patients with $\beta$-thalassemia intermedia and major $[15,16]$. This hypercoagulable state primarily results from abnormalities in pathologic $\mathrm{RBC}$ and platelets, coagulation factor defects (protein $\mathrm{C}$ ) and endothelial inflammation, ultimately leading to thrombosis or other types of vascular disease $[15,16]$. Factor V Leiden mutation (G1691A) have been well established risk factor $[17,18]$ and it is the most prevalent genetic mechanism for inherited hypercoagulable states among the general Caucasian population, with approximately $5 \%$ of the population harboring the mutation [17]. The mutation is caused by a single change from guanine to adenine in the nucleotide 1691 at the exon 10 at the factor $V$ gene of the coagulation cascade. It is associated with a 7 -fold increased risk of venous thrombosis in heterozygote individuals and a 50 -fold to 100 fold increased risk of venous thrombosis in homozygote individuals $[18,19]$. The clinical expression of Factor V Leiden is influenced by coexisting risk factors. Thus, it interacts with external risk factors such as pregnancy, oral contraceptives, surgery, and travel [20]. Oral contraceptives containing an estrogen and a progestogen increase the risk of venous thromboembolism via increased levels of thrombin and fibrin, as well as the levels of almost all coagulation factors [21]. Plasma from patients taking oral contraceptives containing an estrogen and a progestogen is also resistant to the anticoagulation effect of activated protein $\mathrm{C}$, an independent risk factor for venous thromboembolism [21]. Oral contraceptives containing an estrogen and a progestogen also increase the levels of factor VII activating protease, which activates factor VII, thus initiating the extrinsic pathway of the coagulation cascade [21].

LRV thrombosis associated with isolate nutcracker syndrome is a very rare entity, and only 4 cases were found reviewing the literature [1114]. We report a new case in a young female with anterior nutcracker syndrome which debuted with LRV thrombosis. Our patient had a low BMI with two associated genetic prothrombotic risk factors such as thalassemia minor and Factor V Leiden heterozygote mutation and the co-inheritance of both disorders could exacerbate the hypercoagulable state. Since our patient was asymptomatic until received oral contraceptive treatment during 12 months, the concomitant use of oral contraceptives could be considered a trigger factor for venous thrombosis. Thus, it is known that the risk of venous thromboembolism may increase by 30 - to 60 -fold in heterozygous Factor V Leiden carriers taking oral contraceptives [21]. Finally, dehydration produced by vomiting could increase the blood stasis caused by the nutcracker syndrome and could therefore have contributed to the pathogenesis of the thrombosis in this patient.

Four of the 5 reported cases of nutcracker syndrome and thrombosis of LRV (including the present) (Table 1) were young females, 3 with BMI values relatively low. In 4 of the 5 reported cases there was one or several procoagulant risk factors (in one no mentioned): in our case there was two associated genetic prothrombotic risk factors, in one case there was a congenital coagulation mutation (low antithrombin III levels), in one case there was a nephrotic syndrome, in other case there was endometrial cancer, and in other 2 cases there was the antecedent of previous oral contraceptive treatment. In all patient, blood stasis caused by the nutcracker syndrome (in 4 of the 5 cases anterior) may therefore have contributed to the pathogenesis of the LRV thrombosis. The analysis of the 5 reported cases show that the nutcracker syndrome could be a risk factor of LRV thrombosis, but especially if coexist with another thrombogenic factor. CT of the abdomen was the procedure of choice in the diagnosis of the LRV thrombosis and nutcracker syndrome in all cases. It helps to reveal the thrombus extension and is able to evaluate the aorto-mesenteric angle; possible compression and dilation of the LRV; filling defects; endoluminal blood clots; and signs of chronic thrombosis, such as thickening of the vessel walls and calcifications. With regard to the LRV thrombosis management, in all patient oral anticoagulation was the main treatment which resulted in LRV thrombus resolution and/or renal vein recanalization in 4 cases (including our case). In one case the evolution was not reported (Table 1). Recently, has been reported a case of nutcracker syndrome and spermatic vein thrombosis associated to the presence of a factor $\mathrm{V}$ Leiden heterozygous mutation successful resolved with anticoagulation [22]. On the other hand, treatment of the anterior nutcracker syndrome is controversial and different treatment options have been proposed for this syndrome, including follow-up, conservative treatment, and surgical therapy [4,23-25].

\section{Conclusion}

In conclusion, we believe our case to be the first case reporting an association between LRV thrombosis caused by anterior nutcracker syndrome compression with several associated hypercoagulable state risk factors (genetic and acquired) such as: thalassemia minor, Factor V Leiden heterozygosity and oral contraceptive treatment.

Table 1. Summary of the reported cases of nutcracker syndrome complicated by LRV thrombosis

\begin{tabular}{|c|c|c|c|c|c|c|}
\hline Author & Sex & Age & Thrombogenic factor & Location & Treatment & Outcome \\
\hline Cakir, et al. [11] & M & 36 & $\begin{array}{l}\text { Membranous glomerulonephritis with } \\
\text { nephrotic syndrome }\end{array}$ & Posterior & $\begin{array}{l}\text { Anticoagulation with heparin followed by } \\
\text { warfarin } 25 \text { days }+ \text { immunosupressors }\end{array}$ & $\begin{array}{l}\text { Resolution of the thrombus } \\
\text { Proteinuria decreased to } 1 \mathrm{~g} / 24 \mathrm{~h}\end{array}$ \\
\hline Mallat, et al. [12] & F & 24 & Not reported & Anterior & $\begin{array}{l}\text { Anticoagulation with heparin followed by } \\
\text { warfarin during } 6 \text { months }\end{array}$ & $\begin{array}{l}\text { Resolution of the thrombus at } 3 \\
\text { weeks }\end{array}$ \\
\hline Mahmood, et al. [13] & $\mathrm{F}$ & 27 & $\begin{array}{l}\text { Oral contraceptives } \\
\text { Low antithrombin III levels }\end{array}$ & Anterior & $\begin{array}{l}\text { Stop oral contraceptives } \\
\text { Anticoagulation with heparin followed by } \\
\text { warfarin during } 6 \text { months }\end{array}$ & No report about evolution \\
\hline Nakashima, et al. [14] & F & 43 & Cancer & Anterior & Anticoagulation & Resolution \\
\hline Current report & F & 24 & $\begin{array}{l}\text { Oral contraceptives } \\
\text { Thalassemia minor } \\
\text { Heterozygous Factor V Leiden }\end{array}$ & Anterior & $\begin{array}{l}\text { Stop oral contraceptives } \\
\text { Anticoagulation with bemiparin followed by } \\
\text { acenocoumarol for } 23 \text { months }\end{array}$ & $\begin{array}{l}\text { Resolution of the thrombus } \\
\text { Renal vein recanalization }\end{array}$ \\
\hline
\end{tabular}


This case and other studies clearly demonstrate that LRV thrombosis must be evaluated for thrombophilia conditions. Thus, we would like to alert to our colleagues the necessity of checking for more than one pathogenic cause in LRV thrombosis. Treatment of renal vein thrombosis is anticoagulation, while thrombolysis and thrombectomy is only reserved for selected cases. In our opinion, the most appropriate treatment approach is long-term oral anticoagulation in those patients with thrombophilia, with a strong recommendation to avoid additional thrombosis risk factors such as smoking, hormonal contraceptives, immobilization or unusual physical activity. In case of pregnancy appropriate follow-up also should be recommended. However, more individuals treated with anticoagulation will need to support this fact.

\section{References}

1. Ananthan K, Onida S, Davies AH (2017) Nutcracker syndrome: An update on current diagnostic criteria and management guidelines. Eur J Vasc Endovasc Surg 53: 886-894.

2. Berthelot JM, Douane F, Maugars Y, Frampas E (2017) Nutcracker syndrome: A rare cause of left flank pain that can also manifest as unexplained pelvic pain. Joint Bone Spine 84: 557-562.

3. Russo D, Minutolo R, Iaccarino V, Andreucci M, Capuano A, et al. (1998) Gross hematuria of uncommon origin: the nutcracker syndrome. Am J Kidney Dis 32: E3.

4. Velasquez CA, Saeyeldin A, Zafar MA, Brownstein AJ, Erben Y (2018) A systematic review on management of nutcracker syndrome. J Vasc Surg: Venous and Lym Dis 6: 271-278.

5. Choudhary A, Majee P, Gupta R, Basu S, Das RK (2016) Adult idiopathic renal vein thrombosis mimicking acute pyelonephritis. J Clin Diagn Res 10: PD18-PD19.

6. Asghar M, Ahmed K, Shah SS, Siddique MK, Dasgupta P, et al. (2007) Renal vein thrombosis. Eur J Vasc Endovasc Surg 34: 217-223.

7. Wang Y, Chen S, Wang W, Liu J, Jin B (2015) Renal vein thrombosis mimicking urinary calculus: a dilemma of diagnosis. BMC Urol 15: 61.

8. Monie DD, DeLoughery EP (2017) Pathogenesis of thrombosis: Cellular and pharmacogenetic contributions. Cardiovasc Diagn Ther 7: S291-S298.

9. Queiroz RM, Garcia DP, da Costa MJB, Febronio EM (2017) Left renal vein thrombosis secondary to compression by the uncinate process of the pancreas, mimicking the nutcracker syndrome. Radiol Bras 50: 205-220.

10. Yoshida R de A, Yoshida WB, Costa RF, Nacif MS, Sobreira ML, et al. (2016) Nutcracker syndrome and deep venous thrombosis in a patient with duplicated inferior vena cava. J Vasc Surg Venous Lymphat Disord 4: 231-235.
11. Cakir B, Arinsoy T, Sindel S, Bali M, Akcali Z, et al. (1995) A case of renal vein thrombosis with posterior nutcracker syndrome. Nephron 69: 476-477.

12. Mallat F, Hmida W, Jaidane M, Mama N, Mosbah F (2013) Nutcracker syndrome complicated by left renal vein thrombosis. Case Rep Urol 2013: 168057.

13. Mahmood SK, Oliveira GR, Rosovsky RP (2013) An easily missed diagnosis: flank pain and nutcracker syndrome. BMJ Case Rep 2013.

14. Nakashima T, Sahashi Y, Kanamori H, Ohno Y, Okura H (2020) Localized solitary left renal vein thrombus complicating nutcracker syndrome: a case report and review of the literature. CEN Case Rep 10.1007/s13730-020-00467-9.

15. Taher AT, Otrock ZK, Uthman I, Cappellini MD (2008) Thalassemia and hypercoagulability. Blood Rev 22: 283-292.

16. Abosdera MM, Almasry AE, Abdel-Moneim ES (2017) Coagulation defects in thalassemic patients. Pediatr Neonatol 58: 421-424.

17. Taher AT, Cappellini MD, Bou-Fakhredin R, Coriu D, Musallam KM (2018) Hypercoagulability and vascular disease. Hematol Oncol Clin North Am 32: 237-245.

18. Ridker PM, Hennekens CH, Lindpaintner K, Stampfer MJ, Eisenberg PR, et al. (1995) Mutation in the gene coding for coagulation factor $\mathrm{V}$ and the risk of myocardial infarction, stroke, and venous thrombosis in apparently healthy men. $N$ Engl $J$ Med 332: 912-917.

19. Shafia S, Zargar MH, Khan N, Ahmad R, Shah ZA, et al. (2018) High prevalence of factor V Leiden and prothrombin G20101A mutations in Kashmiri patients with venous thromboembolism. Gene 654: 1-9.

20. Robertson L, Wu O, Langhorne P, Twaddle S, Clark P, et al. (2006) Thrombophilia in pregnancy: a systematic review. Br J Haematol 132: 171-196.

21. Andersen BS, Olsen J (1998) Oral contraception and factor V Leiden mutation in relation to localization of deep vein thrombosis. Thromb Res 90: 191-194.

22. Pérez-Ardavín J, Serrano Durbá A, Miró I, Conca Baena MA, March-Villalba JA, et al (2020) Spontaneous spermatic vein thrombosis in pediatric patients: A condition to be considered. Cir Pediatr 33: 99-101.

23. Kawaguchi N, Iwaki T, Wakabayashi T, Sanomura T, Kusaka T (2019) Balloon angioplasty in a pediatric patient with nutcracker syndrome. Pediatr Int 61: 300-301.

24. de Macedo GL, Dos Santos MA, Sarris AB, Gomes RZ (2018) Diagnosis and treatment of the nutcracker syndrome: a review of the last 10 years. J Vasc Bras 17: 220-228.

25. Hao J, Shi H, Xu H, Zhu J, Zhou J, et al. (2019) Ultrasound-assisted microsurgical left spermatic-inferior epigastric vein anastomosis for treating nutcracker syndromeassociated varicocele. Int Urol Nephrol 51: 1925-1932.

Copyright: (C2020 Peces R. This is an open-access article distributed under the terms of the Creative Commons Attribution License, which permits unrestricted use, distribution, and reproduction in any medium, provided the original author and source are credited. 